\title{
Associations of an empirical dietary pattern with cardiometabolic risk factors in Malaysian adolescents
}

\author{
Nor Aishah Emi ${ }^{1}$, Wan Ying Gan', Zalilah Mohd Shariff', Azriyanti Anuar Zaini², Nurainul Hana Shamsuddin, \\ Mahenderan Appukutty ${ }^{4}$ and Geeta Appannah ${ }^{1 *}$
}

\begin{abstract}
s
Background: This study aimed to identify a dietary pattern (DP) characterised mainly by high intakes of free sugar and other nutrients hypothesised to be associated with obesity such as dietary energy density (DED), percentage of energy from total fat and fibre density in adolescents from three southern states of Peninsular Malaysia, and its associations with cardiometabolic risk factors.

Methods: This is a cross-sectional study among 335 adolescents who provided both dietary information assessed using a validated food frequency questionnaire (FFQ) and biochemical parameters including lipid profile, blood glucose, serum insulin and homeostatic model assessment-insulin resistance (HOMA-IR). Anthropometric measurements included weight $(\mathrm{kg})$, height $(\mathrm{cm})$ and waist circumference $(\mathrm{cm})$, while body mass index $(\mathrm{BMI}) \mathrm{in} \mathrm{kg} /$ $\mathrm{m}^{2}$ was estimated, respectively. Reduced rank regression (RRR) identified a DP with percentage of energy from sugar and total fat, DED and fibre density intake as response variables.

Results: The identified 'high sugar, high fibre, high DED and low fat' DP was characterised by high intakes of sugarsweetened beverages, fruits, sweets and low intakes of meat and cereal. Adolescents in the highest tertile of the identified DP had about $3.0(\mathrm{OR}=2.7 ; 95 \% \mathrm{Cl}: 1.3,5.6)$ and $2.0(\mathrm{OR}=1.9 ; 95 \% \mathrm{Cl}: 1.0,3.5)$ times higher odds of having dyslipideamia or elevated total cholesterol and LDL-cholesterol level, respectively compared to adolescents in the lowest tertile DP after adjusting for sex, school location, maternal education, physical activity, dietary misreporting and BMI z-score. This DP was not significantly associated with overweight and obesity.
\end{abstract}

Conclusions: Higher adherence to a DP characterised mainly by free sugars and DED was associated with greater odds of having dyslipideamia, elevated total cholesterol and LDL-cholesterol levels in Malaysian adolescents.

Keywords: Dietary patterns, Dyslipidemia, Cardiometabolic risk factors, Childhood obesity, Malaysian adolescent

\section{Background}

There is strong evidence that the precursor of adult cardiovascular diseases (CVD) begins in childhood, with obesity being the main risk factor among other cardiometabolic risk factors such as insulin resistance and

\footnotetext{
* Correspondence: geeta@upm.edu.my

${ }^{1}$ Department of Nutrition and Dietetics, Faculty of Medicine and Health Sciences, Universiti Putra Malaysia, Serdang, Selangor, Malaysia

Full list of author information is available at the end of the article
}

dyslipideamia [1-4]. In line with that, a rapid escalating trend of overweight and obesity among Malaysian adolescents was reported in a recent National Health and Morbidity Survey as well as in a systematic review by Majid et al. in 2015 [5-7].

Over the past decades, accumulated number of evidences have been supporting the role of diet as one of the most important modifiable factor for the prevention of CVD including during childhood and adolescence stages

C C The Author(s). 2020 Open Access This article is licensed under a Creative Commons Attribution 4.0 International License, which permits use, sharing, adaptation, distribution and reproduction in any medium or format, as long as you give appropriate credit to the original author(s) and the source, provide a link to the Creative Commons licence, and indicate if changes were made. The images or other third party material in this article are included in the article's Creative Commons licence, unless indicated otherwise in a credit line to the material. If material is not included in the article's Creative Commons licence and your intended use is not permitted by statutory regulation or exceeds the permitted use, you will need to obtain permission directly from the copyright holder. To view a copy of this licence, visit http://creativecommons.org/licenses/by/4.0/. The Creative Commons Public Domain Dedication waiver (http://creativecommons.org/publicdomain/zero/1.0/) applies to the data made available in this article, unless otherwise stated in a credit line to the data. 
[8]. Adolescence is a period of marked physiological, biological and psychological changes, and may be a key time period for the establishment of lifelong dietary habits [9]. Therefore, early identification of specific dietary habits during adolescence might be beneficial for the prevention of CVD later in life. However, there is very limited information on dietary habits and their relationships with cardiometabolic risk factors among Malaysian young people.

Having said that, a few observational studies in the Western countries have evaluated associations between empirically derived dietary patterns (DPs) and cardiometabolic risk factors in adolescents [10-13]. For example, two pregnancy cohort studies in Australia and United Kingdom (UK) reported that a DP characterised by food intakes high in dietary energy density (DED), high fat and low fibre was associated greater adiposity and cardiometabolic risk factors during adolescence in 2010 and 2015, respectively [11, 12]. Because of emerging importance of dietary sugar in the development of obesity, an extension to the UK study was performed in 2016 [12, 14]. It was reported that adolescents with greater adherence to a DP characterised by high intakes of dietary fats and sugar were found to be associated with greater adiposity. Dietary fats and sugar might be associated with overconsumption of energy, and therefore may act as dietary risk factors for the development of obesity and CVD $[14,15]$.

However, given the differences in cultures and dietary habits across the world, it is highly possible that much are remain to be known on dietary patterns and health outcomes, particularly of those countries in the East. To date, no studies have assessed empirical DPs in relation to cardiometabolic risk factors among Malaysian adolescents. In this study, we hypothesised that a DP characterised by response variables linked to obesity namely free sugar, dietary fat, DED, and fibre would be associated with cardiometabolic risk factors among adolescents in Malaysia.

\section{Methods}

\section{Study design and sample}

This cross-sectional study was conducted from August to November 2016 in several public secondary schools that were randomly selected within three states in the southern region of Peninsular Malaysia namely Negeri Sembilan, Melaka and Johor. A probability proportionate sampling design was used for selecting these schools [16]. This was done by obtaining a complete list of public secondary schools and the estimated number of adolescents aged 13 years old in each school (sampling frame) from the Ministry of Education (MOE) Malaysia. In Malaysia, adolescents usually enter public secondary schools at the age of 13 years. This age is important as it represents a key transition period from primary to secondary education levels that correlates with major pubertal changes and increases in personal autonomy (e.g. less parental control and more social freedom), both of which may affect food choices [17]. A total of 24 selected schools were approached and out of these, only 21 schools agreed to participate.

Sample size for this study was estimated using a formula for single cross-sectional survey. The calculation for minimum sample size was based on the prevalence of obesity in children (20.9\%) [18]. After taking into account a $20 \%$ response rate and a design effect of 2, a total number of 1000 adolescents was estimated for this study. Out of the estimated 1000 adolescents, a total of 933 agreed to participate (93\% of response rate). Information on anthropometric, physical activity, dietary assessment and biochemical measurement was provided by $930,793,585$ and 507 adolescents, respectively. Out of these, 336 adolescents provided both cardiometabolic and valid dietary data while 582 adolescents provided both the anthropometric and dietary data. Supplementary Figure 1 illustrates the number of adolescents who provided anthropometric, biochemical, dietary and physical activity data in this study.

Full ethical approval was obtained from the Ethics Committee for Research Involving Human Subjects (JKEUPM) of Universiti Putra Malaysia (UPM) (Reference number: FPSK (EXP16) P031). Approval to conduct this study in the selected schools were obtained from the Ministry of Education Malaysia, state education departments and selected schools. The study respondents and their parents provided written consent before the commencement of the study.

\section{Patient and public involvement}

Prior to the recruitment, adolescents in the selected schools were screened for their eligibility. Adolescents aged 13 years old during the data collection comprised of both sexes, with adequate ability to read and understand Malay or English language were eligible to participate in the study. However, adolescents with physical disabilities and chronic conditions were not eligible to participate in this study. Eligible adolescents were invited to take part in this study and were given a copy of study information sheet. Interested adolescents were asked to sign an assent form after being clearly briefed on all the procedures required for the study. An informed consent form was sent to their parents for further approval. Parents who agreed with the study involvement were asked to complete the parental questionnaire at home and return it to the study researcher through their children. During the second visit to the school, a research team comprised of a dietitian, a medical doctor, and two research enumerators collected various data i.e. socio-demography, dietary, physical activity, anthropometric and biochemical measurements from the study adolescents. 


\section{Dietary assessment}

A validated adolescent food frequency questionnaire (FFQ) was used to assess dietary intakes in the past 12 months and details of this FFQ has been previously described [19]. In brief, the MyUM FFQ was originally developed by a group of researchers from a contemporaneous study to that of this study in Universiti Malaya (UM) [17]. It comprised of 195 food items and is a self-administered questionnaire designed especially for Malaysian secondary school adolescents aged between 13 to 18 years. Before administering the FFQ, step-by-step instructions on how to fill in the questionnaires were given to all participants by the study researchers. As an aid to estimate food intake, the participants were provided with a flipchart on household measurements. The food intake frequency and portion size of each food item were recorded by the adolescents. The average frequency for consumption of each food item over the past year was recorded as 'never', '1-3 times per month', 'one time a week', '2-4 times per week', '5-6 times per week', 'one time a day', '2-3 times per day', '4-5 times per day', or ' $\geq 6$ times per day'. The study researchers checked all the questionnaires upon submission to ensure that all fields were filled in.

The process of converting the FFQ raw data to daily energy and other nutrients were conducted manually using a standard conversion factor to estimate daily food intake based on the frequency of food consumption [20]. The estimation of daily food intake was analysed using the Nutritionist Pro software version 3.1 (Axxya Systems, USA). The dietary data of the food items which were included in the FFQ were derived from the Malaysian Food Composition [21, 22]. Adolescents whose overall dietary energy intake were outside the range of $400-8000 \mathrm{kcal}$ (or 1674$33,472 \mathrm{~kJ}$ ) were excluded from the DP analysis [23].

Dietary misreporting was estimated using the Goldberg eq. (2000) according to the ratio of energy intake (EI) to basal metabolic rate (BMR) [24]. BMR was calculated using a sex-specific formula for Malaysian adolescents aged 13 years [25]. Physical activity level (PAL) was set at 1.55 as majority of adolescents had been reported to have low physical activity levels [26]. The cutoff values for dietary misreporting was calculated based on the confidence limit of agreement between the ratio of EI to BMR and PAL. Adolescents with the ratio of EI to BMR ranging from 1.09 to 2.21 were considered as plausible reporters, otherwise, they were considered as under-reporters or over-reporters, accordingly. Variable on dietary misreporting was included as a potential covariate in statistical models.

\section{Dietary patterns}

Reduced rank regression (RRR) analysis was used to derive empirical DPs using SAS software version 9.4 (SAS Institute, Cary, NC). The RRR is a statistical method to determine linear function of predictor variables (food groups) by maximising the explained variation in nutrients (response variables) related to the disease of interest [27]. All the food items from the FFQ were categorised into 13 food groups (g/d) based on their nutritional characteristics and were used as predictor variables "Supplementary Table 1" [13]. DED, percentage of energy from total fat intake, percentage of energy from total sugar intake and fibre density were selected as response variables. These selected response variables showed significant associations with obesity and other cardiometabolic risk factors in previous prospective studies in Australia and UK [11, 12].

DED was calculated by dividing total food energy (kJ) with total food weight (g) by excluding beverages [13]. Meanwhile, fibre density was determined by absolute fibre intake (g/d) divided by total daily energy intake (MJ) [13]. Percentages of energy from total fat and sugar intakes were expressed by dividing total energy intake from fat $(\mathrm{kJ})$ or total energy intake from free sugar $(\mathrm{kJ})$ by total energy intake (kJ), followed by a multiplication of $100[13,14]$. In this study, dietary sugar was defined as short-chained carbohydrates known as monosaccharide and disaccharides presented naturally in foods such as fruits or in manufactured products such as refined sugar [28].

A separate RRR analysis was applied specifically to investigate any gender variations between the DPs. However, as the DPs derived for both males and females were similar in their factor loading of food groups, thus DPs derived for the total respondents were taken for further analysis. Each adolescent obtained an individual z-score for each DP derived; a higher $\mathrm{z}$-score corresponded to a higher adherence to the identified DP. Z-scores for the identified DP were analysed continuously and categorically (tertiles) with the lowest tertile set as the reference category.

\section{Measurement of cardiometabolic risk factors}

A digital scale (Tanita HD319, Japan) was used to measure the adolescents' body weight in kilogram, while their body height in centimetre was measured using a stadiometer (Seca 206, Germany). A measuring tape (Seca 201, Germany) was used to measure the adolescents' waist circumference (WC) at the midpoint between their lower border of the ribs and their upper border of the pelvis. All measurements were repeated twice to obtain a mean value for each variable which were then used in the analysis.

Adolescents' BMI was estimated by using a standard formula, body weight $(\mathrm{kg})$ divided by the squared measured body height $\left(\mathrm{m}^{2}\right)$. In addition, BMI $\mathrm{z}$-score for age and gender was calculated using the WHO Anthro Software [29]. Overweight and obesity were defined using the BMI $\mathrm{z}$-scores, whereby values of more than one and two standard deviations indicated possible risk of overweight and obesity, respectively. Computed WC z-scores 
were utilised for the analyses of abdominal obesity and was defined according to the Malaysian WC centile [30].

Adolescents who consented for blood withdrawal were asked to fast overnight before venepuncture by a phlebotomist. A total of $10 \mathrm{ml}$ of fasting blood was withdrawn from each adolescent for insulin, fasting blood glucose (FBG), total cholesterol (TC), triglycerides (TG), HDL-C and low-density lipoprotein cholesterol (LDL-C) analyses. Insulin resistance was estimated using Homeostasis Model Assessment (HOMA) [31]. FBG concentration was measured by hexokinase assay using reagent by ADVIA Chemistry Glucose Hexokinase_3 and insulin concentration was measured using two-site sandwich immunoassay by ADVIA Centaur Insulin assay (Siemens Healthcare Diagnostics Inc., Tarrytown NY, USA). TC and HDL-C concentration were measured by enzymatic endpoint method and elimination/catalase method, respectively using reagent by ADVIA Chemistry (Siemens Healthcare Diagnostics Inc., Tarrytown NY, USA). TG concentration was measured by enzymatic reaction method with Trinder endpoint using ADVIA TRIG_2 reagent (Siemens Healthcare Diagnostics Inc., Tarrytown NY, USA). LDL-C and HOMA was calculated using the Friedewald formula (1972) and standard formula by Metthews et al. (1985), respectively [32, 33].

Dyslipidaemia during adolescence was defined when either the study adolescents' TC level was greater than or equal to $5.2 \mathrm{mmol} / \mathrm{L}$ or their LDL-C level was greater than or equal to $3.4 \mathrm{mmol} / \mathrm{L}$ [34]. Adolescents with abnormal biochemical values were classified if their biochemical parameter values were $\geq 5.60 \mathrm{mmol} / \mathrm{L}$ for blood glucose, $\geq 5.20 \mathrm{mmol} / \mathrm{L}$ for total cholesterol, $\leq 1.03 \mathrm{mmol} / \mathrm{L}$ for HDL-cholesterol, $\geq 4.12 \mathrm{mmol} / \mathrm{L}$ for LDL-cholesterol, $\geq 1.70 \mathrm{mmol} / \mathrm{L}$ for triglycerides, $\geq 25.0 \mathrm{uIU} / \mathrm{mL}$ for serum insulin and $\geq 4.0$ unit for HOMA-IR level [34-37].

\section{Covariates}

A set of parents' and study adolescents' socio-demographic information was collected in this study. Parents were requested to complete a self-administered parental questionnaire comprised of information on educational level, occupation and monthly income. Meanwhile, adolescent questionnaire included questions such as date of birth, ethnicity, religion and gender. Self-reported physical activity in the past seven days was assessed using Physical Activity Questionnaire for Older Children (PAQ-C) [38]. PAQ-C has been validated and showed acceptable validity and good internal consistency among Malaysian adolescents $[39,40]$.

\section{Statistical analysis}

Descriptive data were presented in mean \pm standard deviation (SD) for continuous data and in frequency (n) and percentage (\%) for categorical data. Comparisons between genders were performed using independent $\mathrm{t}$-test and chi- square test. Binary logistic regression analysis was conducted to evaluate association between tertiles (2nd tertile vs. 1st tertile and 3rd tertile vs. 1st tertile) of the DP zscores and overweight or obesity, abdominal obesity, dyslipidaemia, elevated values of FBG, TC, LDL-C, TG, insulin, HOMA-IR and low HDL-C. Regression models were conducted for all the cardiometabolic parameters in male and female, separetely due to sex dimorphism and pubertyrelated differences in growth [41]. All the models were adjusted for covariates including gender, school location (rural and urban), mother's educational level (no formal education or primary level, secondary school level and tertiary level), dietary misreporting, physical activity and BMI z-score (for biochemical parameters only). All the above-mentioned analyses were ran using IBM SPSS Statistics software version 23 (IBM Corporation, New York, US) and a $p$-value of $<0.05$ was considered as statistically significant.

\section{Results}

In this study, a total of $68 \%$ of adolescents were females and the predominant ethnic group was Malay (87\%), while the rest were either Chinese (6.8\%), Indian (4.7\%) or belonged to other ethnicity groups $(1.3 \%)$ such as Iban and Kadazan. Adolescents from urban and rural schools were 434 (46.5\%) and 499 (53.5\%), respectively. Only $6 \%$ of the adolescents were from schools of smaller size while the rest of the adolescents were from either medium or larger sized schools. A majority of adolescents' parent reported to have a monthly income of less than RM 5, 228 (88.6\%). Most number of the adolescents' mothers completed their education at secondary school level (73.8\%). Males scored significantly higher physical activity levels compared to females "Table 1".

The total prevalence of overweight or obesity and abdominal obesity in this study was 32.4 and $11.6 \%$, respectively. There were no significant differences observed in BMI $\left(\mathrm{kg} / \mathrm{m}^{2}\right)$ and waist circumference $(\mathrm{cm})$ between the genders. Males showed lower mean values for TC $(\mathrm{mmol} / \mathrm{L})$, HDL-C $(\mathrm{mmol} / \mathrm{L})$ and LDL-C $(\mathrm{mmol} /$ L) levels and a higher FBG $(\mathrm{mmol} / \mathrm{L})$ value compared to females $(P<0.05)$ "Table 2 ".

\section{Dietary patterns}

A total of four DPs was identified and the percentage of variations explained by all response variables were 35,14 , 9 and 1\% for DP1, DP2, DP3 and DP4, respectively "Supplementary Table 2". The first DP was chosen for further analysis as it explained the greatest proportion of the variation in all response variables (35\%) and reflected a dietary pattern that may positively associated with greater obesity risk. The selected DP was positively correlated with DED $(r=0.39)$, percentage of energy from sugar $(r=0.64)$, fibre density $(r=0.61)$ and negatively correlated with percentage of energy from fat $(r=-0.26)$. The identified 'high 
Table 1 Characteristics of study adolescents and their parents recruited from three southern states of Peninsular Malaysia

\begin{tabular}{|c|c|c|c|c|}
\hline \multirow[t]{2}{*}{ Characteristics } & \multicolumn{3}{|l|}{$n(\%)$} & \multirow{2}{*}{$\begin{array}{l}\mathrm{p}- \\
\text { value }\end{array}$} \\
\hline & $\begin{array}{l}\text { Male } \\
(\boldsymbol{n}=300)\end{array}$ & $\begin{array}{l}\text { Female } \\
(\boldsymbol{n}=633)\end{array}$ & Total & \\
\hline \multicolumn{5}{|l|}{ School location } \\
\hline Urban & $147(49.0)$ & $287(45.3)$ & $434(46.5)$ & \multirow[t]{2}{*}{0.29} \\
\hline Rural & $153(51.0)$ & $346(54.7)$ & $499(53.5)$ & \\
\hline \multicolumn{5}{|l|}{ School size } \\
\hline Small ( $\leq 100$ students) & $19(6.3)$ & $39(6.2)$ & $58(6.2)$ & \multirow[t]{3}{*}{0.93} \\
\hline Medium (101-199 students) & $109(36.3)$ & $238(37.6)$ & $347(37.2)$ & \\
\hline Large ( $\geq 200$ students) & $172(57.3)$ & $356(56.2)$ & $528(56.6)$ & \\
\hline \multicolumn{5}{|l|}{ Ethnicity } \\
\hline Malay & $262(87.3)$ & $552(87.2)$ & $814(87.2)$ & \multirow[t]{4}{*}{0.95} \\
\hline Chinese & $21(7.0)$ & $42(6.6)$ & $63(6.8)$ & \\
\hline Indian & $14(4.7)$ & $30(4.7)$ & $44(4.7)$ & \\
\hline Others & $3(1.0)$ & $9(1.4)$ & $12(1.3)$ & \\
\hline \multicolumn{5}{|l|}{ Parental Income, $n=599^{\mathrm{a}}$} \\
\hline Below median & $159(88.3)$ & $372(88.8)$ & $531(88.6)$ & \multirow[t]{2}{*}{0.89} \\
\hline Above median & $21(11.7)$ & $47(11.2)$ & $68(11.4)$ & \\
\hline \multicolumn{5}{|l|}{ Educational level of mother, $n=818$} \\
\hline No formal education/Primary & $23(9.5)$ & $68(11.8)$ & $91(11.1)$ & \multirow[t]{3}{*}{0.58} \\
\hline Secondary school & $179(74.3)$ & $425(73.7)$ & $604(73.8)$ & \\
\hline Higher institution & $39(16.2)$ & $84(14.6)$ & $123(15.0)$ & \\
\hline Physical activity total score, $n=793$ & $2.77( \pm 0.72)$ & $2.40( \pm 0.57)$ & $2.52( \pm 0.64)$ & $<0.001$ \\
\hline 'High sugar, high fibre, high DED and low fat' DP z-score, $n=583$ & $-0.15( \pm 1.14)$ & $0.06( \pm 1.40)$ & $0.00( \pm 1.33)$ & 0.08 \\
\hline
\end{tabular}

${ }^{a}$ Median monthly household income (RM 5, 228) based on Household Income and Basic Amenities Survey 2016. $p<0.05$ considered significant. DED Dietary Energy Density, DP Dietary Pattern

sugar, high fibre, high energy density and low fat' DP was characterised by high intakes of sugar-sweetened beverages (SSB) $(r=0.83)$, fruits $(r=0.33)$, sweets $(r=0.26)$, low intakes of cereal and cereal-based dishes $(r=-0.22)$, as well as, meat and meat dishes $(r=-0.21)$.

\section{Dietary pattern and cardiometabolic risk factors}

No significant associations were observed between the tertiles of DP z-scores and overweight or obesity as well as abdominal obesity among the study adolescents in both unadjusted and adjusted models "Tables 3 and 4". Adolescents in the third tertile of the "high sugar, high fibre, high energy density and low fat' DP $\mathrm{z}$-scores had 2 times higher odds of having elevated $\mathrm{TC}$ level $(\mathrm{OR}=2.3$; $95 \% \mathrm{CI}: 1.2,4.3)$ and elevated LDL-C level $(\mathrm{OR}=1.8$; $95 \% \mathrm{CI}: 1.0,3.0)$, compared to adolescents in the first tertile of DP z-score "Table 3". These associations were further increased after adjusting for confounding factors, whereby adolescents in the highest tertile of DP z-scores had about $3(\mathrm{OR}=2.7 ; 95 \% \mathrm{CI}: 1.3,5.6)$ and $2(\mathrm{OR}=1.9$; $95 \%$ CI: 1.0, 3.5) times higher odds of having elevated TC and LDL-C levels, compared to adolescents in the lowest tertile of DP z-scores "Table 4". Similarly, adolescents in the highest tertile of the identified DP-zscores showed 3 times $(\mathrm{OR}=2.7 ; 95 \% \mathrm{CI}: 1.3,5.6)$ higher odds of having dyslipideamia compared to adolescents in the lowest tertile, after adjusting for confounders "Table 4".

\section{Discussion}

The identified 'high sugar, high fibre, high energy density and low fat' DP in this study was associated with higher odds of having elevated TC, LDL-C levels and dyslipidaemia in adolescents aged 13 years in Malaysia.

Despite the similarities on the DP assessment (RRR) and response variables, DP identified in this study differed from those characterised in a previous study among the UK children, explicitly the Avon Longitudinal Study of Parents and Children (ALSPAC) [14]. In the ALSPAC study, two DPs namely the "high energy density, high sugar, high fat and low fibre' DP and 'non-energy density, high sugar, low fat' DP were identified. Nevertheless, the DPs identified in the current study as well as in the ALSPAC study were characterised mainly by foods high in sugar and therefore suggesting major role of sugar in an adolescent's diet, at least in the studies from these two countries. 
Table 2 Anthropometric and biochemical characteristics of adolescents aged 13 years recruited from three southern states of Peninsular Malaysia

\begin{tabular}{|c|c|c|c|c|}
\hline \multirow[t]{2}{*}{ Characteristics } & \multirow{2}{*}{$\begin{array}{l}\text { Male } \\
\text { Mean (SD) }\end{array}$} & \multirow{2}{*}{$\begin{array}{l}\text { Female } \\
\text { Mean (SD) }\end{array}$} & \multirow{2}{*}{$\begin{array}{l}\text { Total } \\
\text { Mean (SD) }\end{array}$} & \multirow[t]{2}{*}{$p$-value } \\
\hline & & & & \\
\hline Height $(\mathrm{cm}), n=930$ & $155.4( \pm 8.5)$ & $153.0( \pm 5.9)$ & $153.8( \pm 6.9)$ & $<0.001$ \\
\hline Weight (kg), $n=930$ & $49.8( \pm 14.6)$ & $48.6( \pm 13.1)$ & $49.0( \pm 13.6)$ & 0.20 \\
\hline BMI $\left(\mathrm{kg} / \mathrm{m}^{2}\right), n=930$ & $20.5( \pm 5.3)$ & $20.6( \pm 5.0)$ & $20.6( \pm 5.1)$ & 0.65 \\
\hline BMI z-score, $n=930$ & $0.37( \pm 1.57)$ & $0.26( \pm 1.48)$ & $0.29( \pm 1.51)$ & 0.30 \\
\hline WC (cm), $n=929$ & $66.7( \pm 13.5)$ & $65.0( \pm 10.8)$ & $65.5( \pm 11.7)$ & 0.05 \\
\hline WC z-score, $n=929$ & $0.10( \pm 1.15)$ & $-0.05( \pm 0.92)$ & $0.00( \pm 1.00)$ & 0.03 \\
\hline Fasting Blood Glucose (mmol/L), $n=507$ & $4.93( \pm 0.39)$ & $4.83( \pm 0.42)$ & $4.86( \pm 0.42)$ & 0.02 \\
\hline Total cholesterol $(\mathrm{mmol} / \mathrm{L}), n=507$ & $4.36( \pm 0.72)$ & $4.71( \pm 0.79)$ & $4.60( \pm 0.79)$ & $<0.001$ \\
\hline $\mathrm{HDL}$ cholesterol (mmol/L), $n=507$ & $1.48( \pm 0.32)$ & $1.58( \pm 0.32)$ & $1.55( \pm 0.33)$ & 0.003 \\
\hline LDL cholesterol (mmol/L), $n=507$ & $2.47( \pm 0.63)$ & $2.73( \pm 0.70)$ & $2.65( \pm 0.69)$ & $<0.001$ \\
\hline Triglycerides $(\mathrm{mmol} / \mathrm{L}), n=507$ & $0.88( \pm 0.54)$ & $0.89( \pm 0.38)$ & $0.89( \pm 0.44)$ & 0.78 \\
\hline Serum insulin (ulU/mL), $n=507$ & $14.14( \pm 9.07)$ & $13.96( \pm 8.08)$ & $14.02( \pm 8.38)$ & 0.83 \\
\hline \multirow[t]{2}{*}{ HOMA-IR (unit), $n=507$} & $3.14( \pm 2.20)$ & $3.03( \pm 1.83)$ & $3.06( \pm 1.95)$ & 0.55 \\
\hline & $n(\%)$ & $n(\%)$ & $n(\%)$ & $p$-value \\
\hline Overweight/obesity, $n=930$ & $103(34.6)$ & $198(31.4)$ & $301(32.4)$ & 0.11 \\
\hline Abdominal obesity, $n=929$ & $35(11.8)$ & 73 (11.6) & $108(11.6)$ & 0.92 \\
\hline Dyslipidaemia, $n=507$ & $22(14.3)$ & $99(28.0)$ & $121(23.9)$ & $0.001^{a}$ \\
\hline Plausible dietary reporter, $n=585$ & $54(31.4)$ & $117(28.5)$ & $171(29.2)$ & 0.11 \\
\hline
\end{tabular}

The identified DP in this study was characterised by high consumption of SSB, fruit and sweet with lower consumption of cereal and cereal-based dishes, as well as, meat and meat dishes. This is in line with a review on added sugar intake among Malaysian adolescents whereby a high frequency of sugary foods and beverages intake for breakfast and during snacking times was reported [42]. The common sweetened foods and beverages frequently consumed (more than twice a week) by Malaysian adolescents include carbonated drinks, fruit juices, caffeinated and chocolate drinks, biscuits, candies, ice cream and cakes [43]. On the other hand, a higher SSB intake among Malaysian adolescents aged 13 years in Kuala Lumpur was found to be associated with increased levels of FBG, TG, insulin and HOMA-IR and decreased HDL-C level [44]. The excessive intake of sugar (sucrose, fructose, high fructose corn syrup) can directly affect the regulation of lipid and carbohydrate metabolism or it can affect the metabolism indirectly by promoting continuous positive energy balance and gradual weight gain over the long term [45].

The findings from this study were in line with a recent review that have evaluated the effect of dietary sugar on cardiometabolic risk in adults [46]. It was demonstrated that the replacement of fat intake with refined carbohydrate was associated with elevated blood lipids and blood pressure [46, 47]. This is a particular concern as refined carbohydrates (added sugar and SSB) have been also linked to the risk of heart disease due to its large consumption $[48,49]$. Although it is quite natural to experience peaks in TC and LDL-C levels during adolescence, an elevated LDL-C during adolescence was a significant predictor for $38 \%$ of dyslipidaemia cases in adulthood [50].

The positive correlation observed between the identified DP and higher fruit intakes contradicted findings from the Western countries [11, 14, 51]. Nevertheless, this correlation is consistent with the pattern of fruit intakes in other studies conducted among the Malaysian adolescents [52, 53]. For instance, a cross-sectional namely the South East Asian Nutrition Surveys (SEANUTS Malaysia) study reported that a total of 1773 children aged between 7 to 9 years reported to have achieved $14 \%$ of the recommended daily fruit intake (2 servings), while children aged between 10 and 12 years consumed $20 \%$ as per the recommendation [52]. Another crosssectional study in 454 adolescents aged 12 to 19 years in 
Table 3 Unadjusted associations [odds ratio (95\% Cl)] between 'high sugar, high fibre, high energy density and low fat' DP z-scores and cardiometabolic risk factors in adolescents aged 13 years recruited from three southern states of Peninsular Malaysia

\begin{tabular}{|c|c|c|c|c|c|c|}
\hline \multirow[t]{2}{*}{ Cardiometabolic risk factors } & \multicolumn{2}{|l|}{ Male } & \multicolumn{2}{|l|}{ Female } & \multicolumn{2}{|l|}{ Total } \\
\hline & $\begin{array}{l}\text { 2nd tertile vs 1st } \\
\text { tertile }\end{array}$ & $\begin{array}{l}\text { 3rd tertile vs 1st } \\
\text { tertile }\end{array}$ & $\begin{array}{l}\text { 2nd tertile vs 1st } \\
\text { tertile }\end{array}$ & $\begin{array}{l}\text { 3rd tertile vs 1st } \\
\text { tertile }\end{array}$ & $\begin{array}{l}\text { 2nd tertile vs } 1 s t \\
\text { tertile }\end{array}$ & $\begin{array}{l}\text { 3rd tertile vs 1st } \\
\text { tertile }\end{array}$ \\
\hline Overweight/Obese, $n=582$ & $0.9(0.4,1.9)$ & $0.7(0.3,1.6)$ & $0.9(0.5,1.5)$ & $0.8(0.5,1.4)$ & $0.9(0.6,1.4)$ & $0.8(0.5,1.2)$ \\
\hline Abdominal Obesity, $n=581$ & $0.8(0.3,2.7)$ & $1.5(0.5,4.5)$ & $0.9(0.5,1.9)$ & $0.4(0.19,1.0)$ & $0.9(0.5,1.7)$ & $0.7(0.4,1.3)$ \\
\hline Dyslipidaemia, $n=336$ & $0.7(0.1,3.9)$ & $2.9(0.8,10.9)$ & $1.9(0.9,3.9)$ & $2.0(0.9,4.2)$ & $1.7(0.9,3.3)$ & $2.3^{*}(1.2,4.3)$ \\
\hline $\begin{array}{l}\text { Elevated blood glucose }(\geq 5.60 \mathrm{mmol} / \\
\text { L), } n=336\end{array}$ & $4.5(0.4,45.7)$ & $8.1(0.9,73.8)$ & $0.0(0.0,0.0)$ & $0.9(0.2,3.8)$ & $0.6(0.1,2.5)$ & $2.0(0.6,6.1)$ \\
\hline $\begin{array}{l}\text { Elevated total cholesterol }(\geq 5.20 \\
\mathrm{mmol} / \mathrm{L}), n=336\end{array}$ & $0.7(0.1,3.9)$ & $2.9(0.8,10.9)$ & $1.9(0.9,3.9)$ & $2.0(0.9,4.2)$ & $1.7(0.9,3.3)$ & $2.3^{*}(1.2,4.3)$ \\
\hline $\begin{array}{l}\text { Lower HDL-cholesterol level }(\leq 1.03 \\
\mathrm{mmol} / \mathrm{L}), n=336\end{array}$ & $0.7(0.1,7.9)$ & $3.0(0.5,17.9)$ & $0.3(0.1,1.8)$ & $0.5(0.1,2.3)$ & $0.4(0.1,1.7)$ & $1.0(0.4,3.1)$ \\
\hline $\begin{array}{l}\text { Elevated LDL-cholesterol }(\geq 4.12 \\
\mathrm{mmol} / \mathrm{L}), n=336\end{array}$ & $1.2(0.4,3.1)$ & $2.1(0.8,5.4)$ & $1.6(0.9,3.1)$ & $1.6(0.8,3.0)$ & $1.6(0.9,2.6)$ & $1.8^{*}(1.0,3.0)$ \\
\hline $\begin{array}{l}\text { Elevated triglycerides }(\geq 1.70 \mathrm{mmol} / \mathrm{L}) \text {, } \\
n=336\end{array}$ & $0.7(0.1,7.9)$ & $0.7(0.1,7.9)$ & $2.7(0.3,26.6)$ & $4.9(0.6,42.7)$ & $1.4(0.3,6.2)$ & $2.2(0.5,8.8)$ \\
\hline $\begin{array}{l}\text { Elevated serum insulin ( } \geq 25.0 \mathrm{ulU} / \mathrm{mL}) \\
n=336\end{array}$ & $1.4(0.2,10.6)$ & $4.0(0.7,22.1)$ & $0.6(0.2,2.0)$ & $0.6(0.2,2.1)$ & $0.8(0.8,2.1)$ & $1.2(0.5,3.0)$ \\
\hline $\begin{array}{l}\text { Abnormal HOMA-IR level ( } \geq 4.0 \text { unit), } \\
n=336\end{array}$ & $2.4(0.7,22.1)$ & $4.1^{*}(1.1,14.8)$ & $1.2(0.6,2.5)$ & $0.9(0.4,1.9)$ & $1.5(0.8,2.8)$ & $1.4(0.7,2.6)$ \\
\hline
\end{tabular}

${ }^{*} p<0.05$ is considered significant. HDL-C High Density Lipoprotein Cholesterol, LDL-C Low Density Lipoprotein Cholesterol, HOMA-IR Homeostatic Model Assessment of Insulin Resistance

Table 4 Adjusted associations [odds ratio (95\% Cl)] between 'high sugar, high fibre, high energy density and low fat' DP z-scores and cardiometabolic risk factors in adolescents aged 13 years recruited from three southern states of Peninsular Malaysia

\begin{tabular}{|c|c|c|c|c|c|c|}
\hline \multirow[t]{2}{*}{ Cardiometabolic risk factors* } & \multicolumn{2}{|l|}{ Male, $n=173$} & \multicolumn{2}{|l|}{ Female, $n=412$} & \multicolumn{2}{|l|}{ Total, $n=583^{a}$} \\
\hline & $\begin{array}{l}\text { 2nd tertile vs 1st } \\
\text { tertile }\end{array}$ & $\begin{array}{l}\text { 3rd tertile vs 1st } \\
\text { tertile }\end{array}$ & $\begin{array}{l}\text { 2nd tertile vs 1st } \\
\text { tertile }\end{array}$ & $\begin{array}{l}\text { 3rd tertile vs 1st } \\
\text { tertile }\end{array}$ & $\begin{array}{l}\text { 2nd tertile vs 1st } \\
\text { tertile }\end{array}$ & $\begin{array}{l}\text { 3rd tertile vs 1st } \\
\text { tertile }\end{array}$ \\
\hline Overweight/Obese, $n=452$ & $1.2(0.5,3.1)$ & $0.6(0.2,1.8)$ & $1.0(0.5,1.8)$ & $0.9(0.5,1.6)$ & $1.0(0.6,1.7)$ & $0.9(0.5,1.4)$ \\
\hline Abdominal Obesity, $n=452$ & $0.9(0.2,4.3)$ & $0.9(0.2,4.5)$ & $0.8(0.3,1.8)$ & $0.5(0.2,1.2)$ & $0.9(0.4,1.9)$ & $0.7(0.3,1.6)$ \\
\hline Dyslipidaemia, $n=283$ & $0.9(0.1,8.8)$ & $3.2(0.5119 .0)$ & $2.1(0.9,4.6)$ & $2.2(0.9,5.0)$ & $2.0(0.9,4.2)$ & $2.7^{*}(1.3,5.6)$ \\
\hline $\begin{array}{l}\text { Elevated blood glucose ( } \geq 5.60 \mathrm{mmol} / \\
\mathrm{L}), n=283\end{array}$ & $0.0(0.0,0.0)$ & $0.0(0.0,0.0)$ & $0.0(0.0,0.0)$ & $0.5(0.1,4.2)$ & $1.0(0.25 .9)$ & $3.2(0.7,15.4)$ \\
\hline $\begin{array}{l}\text { Elevated total cholesterol }(\geq 5.20 \\
\mathrm{mmol} / \mathrm{L}), n=283\end{array}$ & $0.9(0.1,8.8)$ & $3.2(0.5119 .0)$ & $2.1(0.9,4.6)$ & $2.2(0.9,5.0)$ & $2.0(0.9,4.2)$ & $2.7^{*}(1.3,5.6)$ \\
\hline $\begin{array}{l}\text { Lower HDL-cholesterol level }(\leq 1.03 \\
\mathrm{mmol} / \mathrm{L}), n=283\end{array}$ & $0.0(0.0,0.0)$ & $1.2(0.1,19.0)$ & $0.0(0.0,0.0)$ & $0.5(0.1,3.0)$ & $0.0(0.0,0.0)$ & $1.2(0.3,4.1)$ \\
\hline $\begin{array}{l}\text { Elevated LDL-cholesterol }(\geq 4.12 \\
\mathrm{mmol} / \mathrm{L}), n=283\end{array}$ & $1.5(0.4,5.2)$ & $3.2(0.9,11.2)$ & $1.6(0.8,3.3)$ & $1.5(0.7,3.1)$ & $1.7(0.9,3.0)$ & $1.9^{*}(1.0,3.5)$ \\
\hline $\begin{array}{l}\text { Elevated triglycerides }(\geq 1.70 \mathrm{mmol} / \mathrm{L}) \text {, } \\
n=283\end{array}$ & $0.0(0.0,0.0)$ & $0.2(0.0,31.7)$ & $1.6(0.1,19.1)$ & $3.7(0.4,37.1)$ & $0.6(0.1,3.7)$ & $2.1(0.4,9.8)$ \\
\hline $\begin{array}{l}\text { Elevated serum insulin ( } 225.0 \mathrm{ul} / \mathrm{mL} \text { ), } \\
n=283\end{array}$ & $1.1(0.0,25.7)$ & $9.8(0.4222 .8)$ & $0.5(0.1,2.2)$ & $0.6(0.1,2.5)$ & $0.6(0.2,2.0)$ & $1.2(0.4,3.6)$ \\
\hline $\begin{array}{l}\text { Abnormal HOMA-IR level ( } \geq 4.0 \text { unit), } \\
n=283\end{array}$ & $1.8(0.3,12.0)$ & $4.6(0.7,28.6)$ & $1.4(0.6,3.4)$ & $0.9(0.3,2.2)$ & $1.7(0.8,3.6)$ & $1.3(0.6,3.0)$ \\
\hline
\end{tabular}

Model adjusted for school location, mother's educational level, dietary misreporting, physical activity and BMI (for blood biomarker only) ${ }^{\mathrm{a}}$ Model adjusted for sex, school location, mother's educational level, dietary misreporting, physical activity and BMI (for blood biomarker only). ${ }^{*} p<0.05$ is considered significant. $H D L-C$ High Density Lipoprotein Cholesterol, LDL-C Low Density Lipoprotein Cholesterol, HOMA-IR Homeostatic Model Assessment of Insulin Resistance 
Kelantan, Malaysia also reported that older adolescents were more likely to choose healthy foods such as fruits, vegetables and dairy products compared to their younger counterparts [54]. Nevertheless, it is quite common in Malaysia that a few type of fruits are eaten as a fried item e.g. banana or jackfruit fritters, therefore an increase in the consumption of fruits in this study could be due to the misconception of fried fruits as a healthy food intake [43].

Fruits are known to be rich in fibre and antioxidant contents and are perceived as a healthy snack by all age groups including adolescents [55]. Evidence suggested that an increase fibre intake may provide protection against cardiometabolic risk factors in adults [56]. Although the DP identified in this study was characterised by the favourable aspect of high fibre intake from fruits, it was mainly characterised by tropical fruits available in Malaysia such as papaya, guava, pear, starfruit, mango, banana, lanzones, durian, jackfruit and rambutan, which are high in fructose (sugar) as compared to non-tropical fruits such as apples and oranges $[57,58]$. A lower correlation coefficient between percentage of energy from total fat and the identified DP in this study may be due to the compensation of low dietary fat intakes with high free sugar intakes.

Although the selected response variables were previously linked to obesity, the identified DP was not associated with overweight or obesity and abdominal obesity in this study [12]. However, the lack of significant associations seen in the current could be due to the use of BMI and WC instead of fat mass to measure adiposity [11]. Reduction in the final sample size may be another reason for the lack of significant association between the identified DP and obesity in this study. Nonetheless, no significant differences were reported (data not shown) in the anthropometric outcomes and cardiometabolic biomarkers, as well as socio-economic characteristics, particularly maternal education and school location between the total participants and 336 adolescents (with both valid dietary data and biomarkers data) who were included in the multivariate analysis. The present study also reported no significant association between the identified DP and cardiometabolic risk factors specific to any gender, even though, males were reported to have a higher mean FBG level and a lower mean TC, HDL-C and LDL-C levels compared to females. This could be due to differences in the timing of puberty among the study adolescents $[59,60]$.

It is important to note that this study was the first to examine relationships between empirical DPs and cardiometabolic risk factors among Malaysian adolescents. Furthermore, the application of RRR, a-priori method to derive a specific DP and the ability to control for dietary misreporting were also the strengths of this study. Despite these study strengths, there are a few limitations worth mentioning. Firstly, this cross-sectional study was subjected to the possibility of finding significant associations by chance alone. Besides, the findings from this study could not be generalised due to limited coverage of the study location, whereby the study was focused only in the southern region of Peninsular Malaysia. Another limitation of this study is the biases inherent to the dietary assessment method. However, this limitation was minimised by using nutrient densities e.g. DED, fibre density and percentage of energy from fat and sugar as response variables so that errors linked to the dietary assessment method could be reduced [61]. Furthermore, the reduced sample size of the available valid dietary data for the RRR analysis could have influenced the strength of relationships between the identified DP and biochemical parameters. However, this is an unavoidable issue particularly among adolescents and that at this large scale of a study.

\section{Conclusion}

A DP characterised by food intakes high in free sugars and energy density was associated with elevated lipid profiles, particularly cholesterol and LDL-C levels among adolescents aged 13 years in Malaysia. Further longitudinal studies are recommended to strengthen the role of a dietary pattern explained by food intakes high in sugar and energy density in the development of cardiometabolic risk factors in young people in order to design effective health promotion initiatives.

\section{Supplementary information}

Supplementary information accompanies this paper at https://doi.org/10. 1186/s12986-020-00447-x.

Additional file 1: Figure S1. Number of adolescents who provided anthropometric, biochemical, dietary and physical activity data Table S1. Food items included in the food groups selected as predictors in RRR analysis to derive 'high sugar, high fibre, high energy density and low fat' dietary pattern among Malaysian adolescents aged 13 years attending secondary schools Table S2. Characteristics of dietary patterns among Malaysian adolescents aged 13 years attending secondary schools derived using RRR analysis

\section{Abbreviations}

ALSPAC: Avon Longitudinal Study of Parents and Children; BMl: Body mass index; BMR: Basal metabolic rate; CVD: Cardiovascular diseases; DED: Dietary energy density; DP: Dietary pattern; El: Energy intake; FBG: Fasting blood glucose; FFQ: Food frequency questionnaire; HDL-C: High-density lipoprotein cholesterol; HOMA-IR: Homeostasis model assessment; JKEUPM: Universiti Putra Malaysia's ethics committee for research involving human subjects; LDL-C: Low-density lipoprotein cholesterol; PAL: Physical activity level; PAQC: Physical activity questionnaire for older children; Raine: The Western Australian Pregnancy Cohort Study; RRR: Reduced rank regression; SEANUTS: South East Asian Nutrition Surveys; SSB: Sugar-sweetened beverages; TC: Total cholesterol; TG: Triglycerides; WC: Waist circumference; WHO: World Health Organization 


\section{Acknowledgements}

The authors are grateful to all participants and their parents/guardian for their commitments in this study. The authors are also thankful to the respective school staffs for their cooperation in this study.

\section{Authors' contributions \\ NAE was responsible for data collection, data analyses, data interpretation and primary manuscript writing; GWY, ZMS and MA assisted with data interpretation and manuscript writing; AAZ and NHS was responsible for the interpretation of biochemical data and provided critical review of the manuscript; GA was a principal investigator for the study and was responsible for collection of data, conceived the analysis, advised on data analysis, data interpretation and provided critical review of the manuscript data analyses. All authors have read and approved the final manuscript.}

\section{Funding}

This study was funded by a research grant from Ministry of Education Malaysia (FRGS/2/2014/SKK10/UPM/02/10). The first author was supported by the MyMaster programme of Ministry of Higher Education Malaysia and the Graduate Research Fellowship (GRF) programme of Universiti Putra Malaysia. The founding sources had no role in study data collection, analysis and interpretation and preparation of this manuscript.

\section{Availability of data and materials}

The datasets generated and/or analysed during the current study are not publicly available due the raw information gathered in this research were kept strictly confidential as stated in respondents' consent agreement but are available from the corresponding author on reasonable request.

\section{Ethics approval and consent to participate}

Full ethical approval was obtained from the Ethics Committee for Research Involving Human Subjects (JKEUPM) of Universiti Putra Malaysia (UPM) (Reference number: FPSK (EXP16) P031). Approval to conduct this study in the selected schools were obtained from the Ministry of Education Malaysia, state education departments and selected schools. The study respondents and their parents provided written consent before the commencement of the study.

\section{Consent for publication}

All respondents and their parents or guardian provided consent for publication. However, researchers disclosed no names or other identifying information related to respondents and their parents or guardian in this manuscript.

\section{Competing interests}

The authors declare that they have no competing interests.

\section{Author details}

'Department of Nutrition and Dietetics, Faculty of Medicine and Health Sciences, Universiti Putra Malaysia, Serdang, Selangor, Malaysia. ${ }^{2}$ Department of Paediatrics, Faculty of Medicine, University of Malaya, Kuala Lumpur, Malaysia. ${ }^{3}$ Department of Family Medicine, Faculty of Medicine and Health Sciences, Universiti Putra Malaysia, Serdang, Selangor, Malaysia. ${ }^{4}$ Sports Science Programme, Faculty of Sports Science and Recreation, Universiti Teknologi MARA, Shah Alam, Selangor, Malaysia.

\section{Received: 22 December 2019 Accepted: 21 March 2020}

\section{Published online: 07 April 2020}

\section{References}

1. Llewellyn A, Simmonds M, Owen CG, Woolacott N. Childhood obesity as a predictor of morbidity in adulthood: a systematic review and meta-analysis. Obes Rev. 2016;17(1):56-67

2. Nadeau KJ, Maahs DM, Daniels SR, Eckel RH. Childhood obesity and cardiovascular disease: links and prevention strategies. Nat Rev Cardiol [Internet]. 2011;8(9):513-25. Available from: http://www.nature.com/articles/ nrcardio.2011.86

3. Grandemange M, Costet N, Doyen M, Monfort C, Michineau L, Saade M-B, et al. Blood Pressure, Heart Rate Variability, and Adiposity in Caribbean Prepubertal Children. Front Pediatr [Internet]. 2019·7(269):1-13. Available from: https://www.frontiersin.org/article/10.3389/fped.2019.00269/full.
4. Parish RC, Todman S, Jain SK. Resting heart rate variability, inflammation, and insulin resistance in overweight and obese adolescents. Metab Syndr Relat Disord [Internet]. 2016;14(6):291-7. Available from: http://www. liebertpub.com/doi/10.1089/met.2015.0140.

5. Majid HA, Abidin MS, Zamani A, Su T, Mohd Hairi F. Systematic review on the prevalence of overweight and obesity among adolescents in Malaysia 1990-2014. EC Nutr. 2015;2(6):475-82. Available from: https://www. ecronicon.com/ecnu/pdf/ECNU-02-000065.pdf.

6. Institute for Public Health. Nutritional status/Dietary Practices. In: National Health and Morbidity Survey (NHMS) 2011 VOLUME II: Non-communicable diseases [Internet]. Kuala Lumpur: Ministry Of Health; 2011. p. 33-119. Available from: http://www.iku.gov.my/images/IKU/Document/REPORT/ NHMS2011-Volumell.pdf.

7. Institute for Public Health. Nutritional status. In: National Health and Morbidity Survey 2015 VOLUME II: Non-communicable diseases, risk factors \& other health problems [Internet]. Kuala Lumpur: Ministry Of Health; 2015. p. 46-78. Available from: http://www.iku.gov.my/images/IKU/Document/ REPORT/nhmsreport2015vol2.pdf.

8. Waters E, de Silva-Sanigorski A, Burford BJ, Brown T, Campbell KJ, Gao Y, et al. Interventions for preventing obesity in children. Summerbell CD editor. Cochrane Database Syst Rev. 2011;(12):1-212. Available from: http:// doi.wiley.com/10.1002/14651858.CD001871.pub2.

9. Craigie AM, Lake AA, Kelly SA, Adamson AJ, Mathers JC. Tracking of obesityrelated behaviours from childhood to adulthood: a systematic review. Maturitas 2011;70(3):266-284. Available from: http://dx.doi.org/10.1016/j. maturitas.2011.08.005.

10. Huybrechts I, Lioret S, Mouratidou T, Gunter MJ, Manios Y, Kersting M, et al. Using reduced rank regression methods to identify dietary patterns associated with obesity: a cross-country study among European and Australian adolescents. Br J Nutr. 2017:117(2):295-305.

11. Appannah G, Pot GK, Huang RC, Oddy WH, Beilin L, Mori TA, et al. Identification of a dietary pattern associated with greater cardiometabolic risk in adolescence. Nutr Metab Cardiovasc Dis 2015;25(7):643-650. Available from: http://dx.doi.org/https://doi.org/10.1016/j.numecd.2015.04.007.

12. Ambrosini GL, Emmett PM, Northstone K, Howe LD, Tilling K, Jebb SA Identification of a dietary pattern prospectively associated with increased adiposity during childhood and adolescence. Int J Obes. 2012;36(10):1299305 Available from: http://www.ncbi.nlm.nih.gov/pubmed/22868831.

13. Johnson L, Mander AP, Jones LR, Emmett PM, Jebb SA. Energy-dense, lowfiber, high-fat dietary pattern is associated with increased fatness in childhood. Am J Clin Nutr. 2008:87(4):846-54.

14. Ambrosini GL, Johns DJ, Northstone K, Emmett PM, Jebb SA. Free sugars and total fat are important characteristics of a dietary pattern associated with adiposity across childhood and adolescence. J Nutr. 2016;146:778-84.

15. Drewnowski A, Almiron-Roig E. Human Perceptions and Preferences for FatRich Foods. In: Montmayeur JP, Le Coutre J, editors. Fat detection: taste, texture, and post ingestive effects. Boca Raton: CRC Press/Taylor \& Francis; 2010. p. 265-91

16. Aday LA, Cornelius L. Designing and conducting health surveys: a comprehensive guide. 3rd ed. San Francisco: Jossey-Bass; 2006.

17. Coffey A. Relationships: the key to successful transition from primary to secondary school? Improv Sch. 2013;16(3):261-71.

18. Tung SEH, Shamarina S, Mohd Nasir MT. Familial and socio-environmental predictors of overweight and obesity among primary school children in Selangor and Kuala Lumpur. Malays J Nutr. 2011;17(2):151-62.

19. Mohamed K, Tin TS, Yazid M, Jalaludin MY, Al-sadat N, Majid HA. Comparative validity of a food frequency questionnaire (MyUM adolescent FFQ) to estimate the habitual dietary intake of adolescents in Malaysia. Asia Pac J Clin Nutr. 2018;27(4):898-907.

20. Norimah AK, Safiah M, Jamal K, Siti H, Zuhaida H, Rohida S, et al. Food consumption patterns: findings from the Malaysian adult nutrition survey (MANS). Malays J Nutr. 2008;14(1):25-39.

21. Institute for Medical Research. Malaysian Food Composition Database [Internet]. Malaysian Food Composition Database Programme. Available from: http://myfcd.moh.gov.my/ [cited 2017 Jan 12].

22. Majid HA, Ramli L, Ying SP, Su TT, Jalaludin MY. Dietary intake among adolescents in a middle-income country: an outcome from the Malaysian health and adolescents longitudinal research team study (the MyHeART study). PLoS One. 2016;11(5):1-14..

23. Zhang J, Wang $H$, Wang $Y$, Xue $H$, Wang Z, Du W, et al. Dietary patterns and their associations with childhood obesity in China. Br J Nutr. 2015;113(12): 
1978-84 Available from: http://www.journals.cambridge.org/abstract_ S0007114515001154.

24. Black AE. Critical evaluation of energy intake using the Goldberg cut-off for energy intake: basal metabolic rate. A practical guide to its calculation, use and limitations. Int J Obes. 2000;24(9):1119-30.

25. Poh BK, Ismail MN, Zawiah H, Henry C. Predictive equations for the estimation of basal metabolic rate of Malaysian adolescents. Malays J Nutr. 1999;5(1):1-14.

26. Hazreen M, Su T, Jalaludin M, Dahlui M, Chinna K, Ismail M, et al. An exploratory study on risk factors for chronic non-communicable diseases among adolescents in Malaysia: Overview of the Malaysian Health and Adolescents Longitudinal Research Team study (The MyHeART study). BMC Public Health. 2014;14(Suppl 3):S6 Available from: http://www. biomedcentral.com/1471-2458/14/S3/S6.

27. Hoffmann K, Schulze MB, Schienkiewitz A, Nothlings U, Boeing H. Application of a new statistical method to derive dietary patterns in nutritional epidemiology. Am J Epidemiol. 2004;159(10):935-44.

28. Department of Nutrition for Health and Development. Guideline: sugars intake for adults and children [Internet]. World Health Organization. Geneva: WHO press; 2015. p. 1-59. Available from: http://apps.who.int/iris/bitstream/ handle/10665/149782/9789241549028_eng.pdf;jessionid=61 E85434AA63 9D91D566D4FD6D052DFB? sequence=1. [cited 2018 Apr 9].

29. World Health Organization. WHO Anthro (version 3.2.2, January 2011) and macros [Internet]. 2011. Available from: https://www.who.int/childgrowth/ software/en/. [cited 2017 Jan 20].

30. Poh BK, Jannah AN, Chong LK, Ruzita AT, Ismail MN, McCarthy D. Waist circumference percentile curves for Malaysian children and adolescents aged 6.0-16.9 years. Int J Pediatr Obes. $2011 ; 6(3-4): 229-235$. Available from: http://informahealthcare.com/doi/abs/10.3109/17477166.2011.583658.

31. Levy JC, Matthews DR, Hermans MP. Correct homeostasis model assessment (HOMA) evaluation used the computer program. Diabetes Care. 1998;21(12):2191-2.

32. Friedewald WT, Levy RI, Fredrickson DS. Estimation of the concentration of low-density lipoprotein cholesterol in plasma, without use of the preparative ultracentrifuge. Clin Chem. 1972;18(6):499-502.

33. Matthews DR, Hosker JP, Rudenski a S, Naylor B a, Treacher DF, Turner RC. Homeostasis model assessment: insulin resistance and beta-cell function from fasting plasma glucose and insulin concentrations in man. Diabetologia. 1985;28(7):412-9.

34. National Cholesterol Education Program. National Cholesterol Education Program (NCEP): Highlights of the report of the expert panel on blood cholesterol levels in children and adolescents. Pediatrics. 1992;89(3):495-501.

35. Alberti SG, Zimmet P. The IDF consensus definition of the metablic syndrome in children and adolescents: International Diabetes Federation; 2007. p. 24.

36. Lee JM, Okumura MJ, Davis MM, Herman WH, Gurney JG. Prevalence and determinants of insulin resistance among U.S. adolescents: a populationbased study. Diabetes Care. 2006;29(11):2427-32.

37. Florey C, du V, Lowy C, Uppal S. Serum insulin levels in school children aged 9-12 in Westland, Holland. Diabetologia. 1976;12(4):313-7.

38. Kowalski KC, Crocker PRE, Donen RM. The Physical Activity Questionnaire for Older Children (PAQ-C) and Adolescents (PAQ-A) Manual. Saskatoon: College of Kinesiology, University of Saskatchewan; 2004

39. Kowalski KC, Crocker PRE, Faulkner RA. Validation of the physical activity questionnaire for older children. Pediatr Exerc Sci. 1997;9(2):174.

40. Dan S, Zalilah MS, Mohd Nasir MT. Determination of factors associated with physical activity levels among adolescents attending School in Kuantan. Malays J Nutr. 2011;17(2):175-87.

41. Huang RC, Mori TA, Burrows S, Le Ha C, Oddy WH, Herbison C, et al. Sex dimorphism in the relation between early adiposity and cardiometabolic risk in adolescents. J Clin Endocrinol Metab. 2012;97(6):E1014-22.

42. Amarra MSV, Khor GL, Chan P. Intake of added sugar in Malaysia: a review. Asia Pac J Clin Nutr. 2016;25(2):227-40.

43. Boon T, Sedek R. Association between snacking patterns, energy and nutrient intakes, and body mass index among school adolescents in Kuala Lumpur. Am J Food Nutr. 2012;2(3):69-77 Available from: http://www. scihub.org/AJFN/PDF/2012/3/AJFN-2-3-69-77.pdf.

44. Loh DA, Moy FM, Zaharan NL, Jalaludin MY, Mohamed Z. Sugar-sweetened beverage intake and its associations with cardiometabolic risks among adolescents. Pediatr Obes. 2017;12:e1-5.

45. Stanhope KL. Sugar consumption, metabolic disease and obesity: The state of the controversy. Crit Rev Clin Lab Sci. 2016;53:52-67.
46. DiNicolantonio JJ, Lucan SC, O'Keefe JH. The evidence for saturated fat and for sugar related to coronary heart disease. Prog Cardiovasc Dis. 2016;58:464-72.

47. Te Morenga LA, Howatson AJ, Jones RM, Mann J. Dietary sugars and cardiometabolic risk : systematic review and meta-analyses of randomized controlled trials of the effects on blood pressure and lipids 1-3. Am J Clin Nutr. 2014;100(1):65-79.

48. American Heart Association. Dietary fat and its relation to heart attacks and strokes [Internet]. JAMA. 1961 175, Available from: http://jama.jamanetwork. com/article.aspx?doi=10.1001/jama.1961.63040050001011.

49. Temple NJ. Fat, sugar, whole grains and heart disease: 50 years of confusion. Nutrients. 2018;10:39.

50. Magnussen CG, Raitakari OT, Thomson R, Juonala M, Patel DA, Viikari JSA, et al. Utility of currently recommended pediatric dyslipidemia classifications in predicting dyslipidemia in adulthood: evidence from the childhood determinants of adult health (CDAH) study, cardiovascular risk in young Finns study, and Bogalusa heart study. Circulation 2008;117(1):32-42. Available from: http://circ.ahajournals.org/cgi/doi/10.1161/ CIRCULATIONAHA.107.718981.

51. Appannah G, Pot GK, O'Sullivan TA, Oddy WH, Jebb SA, Ambrosini GL. The reliability of an adolescent dietary pattern identified using reduced-rank regression: comparison of a FFQ and $3 \mathrm{~d}$ food record. Br J Nutr. 2014;112(4): 609-15 Available from: http://www.ncbi.nlm.nih.gov/pubmed/25091285.

52. Koo HC, Poh BK, Lee ST, Chong KH, Bragt MCE, Abd TR. Are Malaysian children achieving dietary guideline recommendations? Asia-Pacific J Public Heal. 2016;28:8S-20S.

53. Chong KH, Lee ST, Ng SA, Khouw I, Poh BK. Fruit and vegetable intake patterns and their associations with sociodemographic characteristics, anthropometric status and nutrient intake profiles among Malaysian children aged 1-6 years. Nutrients. 2017;9(8).

54. Abdullah N-F, Teo PS, Foo LH. Ethnic differences in the food intake patterns and its associated factors of adolescents in Kelantan, Malaysia. Nutrients. 2016;8(9):551.

55. Dhingra D, Michael M, Rajput $H$, Patil RT. Dietary fibre in foods: a review. J Food Sci Technol. 2012;49(3):255-66.

56. Threapleton DE, Greenwood DC, Evans CEL, Cleghorn CL, Nykjaer C, Woodhead C, et al. Dietary fibre intake and risk of cardiovascular disease: systematic review and meta-analysis. BMJ. 2013;347:1-12. Available from:. https://doi.org/10.1136/bmj.f6879.

57. Azizah O. Fruits. Nutritious, colourful, yet fragile gift of nature. Serdang: Universiti Putra Malaysia Press; 2011. p. 173.

58. Hii CL, Ong SP, Law CL. Drying studies of tropical fruits cultivated in Malaysia: a review. J Appl Sci. 2011;11(24):3815-20 Available from: http:// www.scialert.net/abstract/?doi=jas.2011.3815.3820.

59. Berentzen NE, Wijga AH, van Rossem L, Postma DS, Gehring U, Smit HA. Pubertal timing and Cardiometabolic markers at age 16 years. J Pediatr 2017;187:158-164. Available from: http://dx.doi.org/10.1016/j.jpeds.2017.04. 008.

60. Guan P, Crabtree D, Peng L, He F, Wang H, Liu Q. The relationship between obesity and body compositions with respect to the timing of puberty in Chongqing adolescents: a cross-sectional study. BMC Public Health. 2017; 17(1):1-7.

61. Michels KB, Bingham SA, Luben R, Welch AA, Day NE. The effect of correlated measurement error in multivariate models of diet. Am J Epidemiol. 2004.

\section{Publisher's Note}

Springer Nature remains neutral with regard to jurisdictional claims in published maps and institutional affiliations. 